\title{
Magnesium pemoline: Facilitation of instrumental avoidance learning
}

A. S. KULKARNI

MEAD JOHNSON RESEARCH CENTER, EVANSVILLE, INDIANA

Acute administration of $5 \mathrm{mg} / \mathrm{kg}$ of magnesium pemoline IP significantly increased the learning of instrumental avoidance in the rat.

Previous studies (Plotnikoff, 1966; Plotnikoff \& Meekma, 1967) have demonstrated that magnesium pemoline enhanced the learning of a conditioned avoldance response in the rat. The effect was demonstrated by using a jump-out avoidance response. A recent study by Cyert et al (1967), however, using a oneway avoidance in an alley, did not show any effect of the same drug on the rate of learning. Since the difference may be the result of the change in the response topography, an examination of the effect of the drug on learning of an entirely different topographical response may prove valuable. It was also of interest to test whether the magnesium pemoline will be effective in normal animals. Plotnikoff (1966) has used "slow learners" to demonstrate the effect of the drug. This report presents data to show that magnesium pemoline enhances acquisition of an instrumental conditioned avoidance response (bar pressing). subjects

The Ss were 24 naive male albino rats of HarlanWistar strain. Their weights ranged from 250-450 $\mathrm{g}$ at the beginning of the experiment.

\section{Apparatus}

Six standard two-lever Skinner boxes (GrasonStadler) were employed. Automatic programming and counting equipment was used throughout the experiment. Procedure

A naive animal was placed in the Skinner box and a chain of trials was initiated. A conditioned stimulus (CS) $-a$ sound and a light-was initiated at the beginning of a trial. The CS continued for $15 \mathrm{sec}$ (or until a response occurred) and ended in an unconditioned stimulus (UCS) -a shock (1.6 mA, $0.5 \mathrm{sec}$ ). The next trial started immediately following the delivery of the UCS. In case of an avoldance, it started immediately following the scheduled point where the UCS would have been delivered. When a response occurred, the next trial started approxdmately 0.5-15 sec after the response. When a response occurred, CS was terminated and UCS was omitted. A total of 400 trials were given to each animal.

Magnesium pemoline (5 mg/kg) was given IP in $0.5 \%$ methocel $30 \mathrm{~min}$ prior to the first trial in a volume of $1 \mathrm{ml} / \mathrm{kg}$. The control animals received the same amount of the vehicle in the same manner.

\section{Results and Discussion}

Animals injected with magnesium pemoline acquired the bar pressing response to avoid shock much faster than those injected with the vehicle alone (Fig. 1). The control animals did show a gradual increment in the learning of the conditioned avoidance response (CAR). The maximal aroidance reached by the control animals was approximately $40 \%$. The group of animals injected with the drug exhibited an avoidance level close to that of the control group, for the first 100 trials. However, all the other avoidance scores obtained by the drug treated animals were much higher than those by the control animals. In animals injected with magnesium pemoline, the increase in the learning probably was greatest between 100 and 200 trials. The differences between the two groups at the end of 200 trials and later were significant $(p<.05)$ using the student's $t$ test. The maxdmal avoidance achieved by drug injected animals was about $70 \%$ at the end of the session in contrast to $40 \%$ avoidance achieved by controls.

The discrepancy between the work by Cyert et al (1967) and Plotnikoff (1966) could be due to the differences between the topographies of the responses.

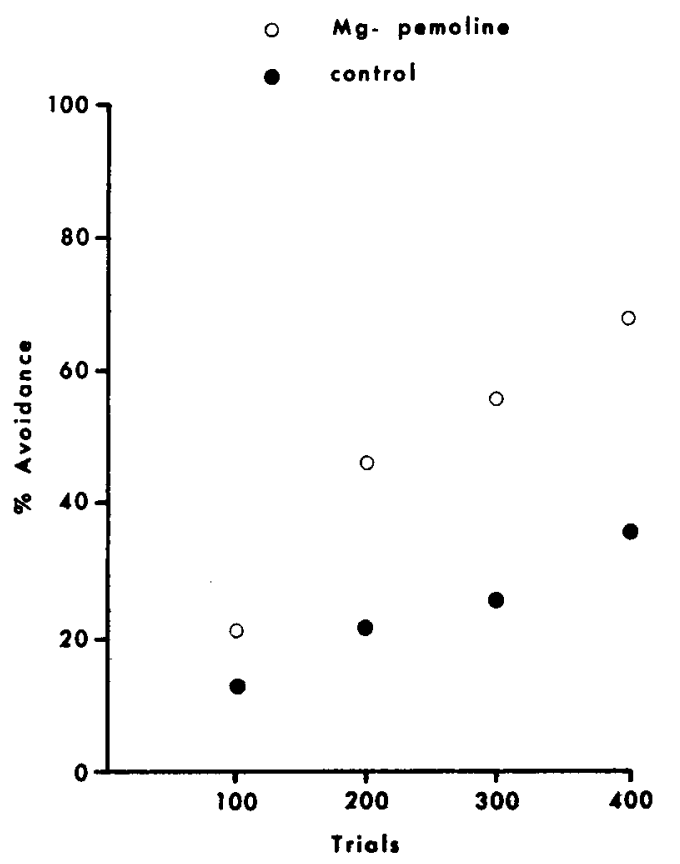

Fig. 1. Percent aroidance response for each block of 100 trials $(N=12$ each). 
It could also be due to the difference in the character of the conditioned stimulus. The first study used no conditioned stimulus other than the apparatus itself. The second study used a buzzer as a part of the conditioned stimulus. (A visual and auditory stimulus is used in our study.) Another difference between their methods is the duration of the conditioned stimulus (5 sec in the first and 30 sec in the second). In our laboratory, when a one-way shuttle box avoidance with 5 sec conditioned stimulus (the shuttle box itself was the CS) was employed, magnesium pemoline and amphetamine were found ineffective in influencing avoidance acquisition. Amphetamine, however, does facilitate the acquisition of the instrumental avoidance response (unpublished results).

An increased reactivity to a conditioned stimulus (Beach \& Kimble, 1967) or a reduction of "freezing" behavior of animals (Frey \& Polidora, 1967) has been proposed to explain the increased acquisition after magnesium pemoline treatment. In our experiment, the latter explanation may not be applicable because the "brief" shock tends to disrupt the freezing behavior. The suggestion that reactivity to a conditioned stimulus is increased after magnesium pemoline, resulting in increased acquisition, may be supported by the finding that when a buzzer was not used as a CS (one-way avoidance) the acquisition of CAR was not increased (Cyert et al, 1967).

Comparative studies with one-way avoidance and instrumental avoidance, with and without the sound as CS should give us further information on the CAR acquisition after magnesium pemoline treatment.

\section{References}

BEACH, G., \& KIMBLE, D. P. Activity and responsibility in rats after magnesium pemoline injections. Science, 1967, 155, 698-701.

CYERT, L. A., MOYER, K. E., \& CHAPMAN, J. A. Effect of magnesium pemoline on learning and memory of a one-way avoidance response. Psychon. Sci, 1967, 7, 9-10.

FREY, P. W., \& POLIDORA, V. J. Magnesium pemoline: Effect on avoidance conditioning in rats. Science, 1967, 155, 1281-1282.

PLOTNIKOFF, N. Magnesium pemoline: Enhancement of learning and memory of a conditioned avoidance response. Science, 1966, 151, 703-704.

PLOTNIKOFF, N., \& MEEKMA, P. J. Pemoline and magnesium hydroxide versus pemoline: Enhancement of learning and memory of a conditioned avoidance response in rats. J. Pharmaceut. Sct., 1967, 56, 290-291. 